\title{
Sports at school: aspect of quality
}

\author{
Dmitry Chernogorov $^{1 *}$, Irina Ryabova ${ }^{2}$, Yuriy Matveev ${ }^{1}$, and Tatyana Sobolevskaya ${ }^{2}$ \\ ${ }^{1}$ Moscow City University, Institute of Natural Science and Sports Technologies, Moscow, Russia \\ ${ }^{2}$ Moscow City University, Institute of System Projects, Moscow, Russia
}

\begin{abstract}
Physical activity is one of the most important means of forming strong health of a child in the conditions of modern school. Currently, after-school sports activities are an integral part of life of the majority of school children. The objective of this study is to assess the state of posture of Moscow primary school children who attend and do not attend various sports clubs after school. The results of the study have shown that the most favorable sports for forming correct posture in children are figure skating, artistic gymnastics, and acrobatics. In these groups, the number of children with incorrect posture is the lowest, at $6.6 \%$ and $25 \%$, respectively. Children involved in sambo and judo have disorders in $39.9 \%$ of cases. A high total percentage of posture disorders has been identified in groups of children engaged in martial arts, such as karate, aikido, and boxing $(64.5 \%)$, sport dance $(78.8 \%)$, and game sports and swimming $(83.1 \%$ and $83.2 \%$, respectively). The data obtained in the study allow us to talk about useful and harmful physical activities for the posture of primary school children. However, the largest number of children with posture disorders $(96.6 \%)$ has been recorded in the group of children who do not participate in sports clubs and whose physical activity is limited only to school physical education lessons.
\end{abstract}

Keywords: school children, sports, photometry, physical activity.

\section{Introduction}

Forming of children's health is one of the most important issues not only in medicine but also in education. According to many authors [1-3], it is particularly important to lay the foundation for good health at a very early age. For example, according to leading specialists in the field of age physiology, the period of 8-10 years old appears to be the most progressive and, at the same time, the most sensitive to the effects of various environmental factors. Therefore, it requires special attention from educators and parents. The life of a child in this period changes completely; the daily routine, nutrition, and school-related workloads increase, and a child spends a long time at the desk during lessons and homework preparation, which has a negative impact on their posture [4]. 25-60\% of children and adolescents already have posture disorders [5-10]. Therefore, physical activity is one of the important means of forming good health in children. It strengthens the musculoskeletal system through its effect on the muscular system [11]. Physical activity

\footnotetext{
${ }^{*}$ Corresponding author: chernogorovdn@mgpu.ru
} 
from early childhood is widely promoted and widespread around the world, which has a definite positive impact on children's health statistics $[12,13]$.

We believe that discussions about the choice of sport should be based on the desire for the comprehensive, harmonious development of a child and the improvement of their physical and functional condition [14]. At the same time, posture is one of the rather informative integral indicators of a child's physical development, which can be used to objectively assess and compare the impact of various physical activities on the degree and quality of children's physical development [15]. Studying the motor activity of school children is an important issue in research aimed at improving the quality of the school system.

The objective of the study is a screening assessment of the posture in Moscow primary school children who attend and do not attend various sports clubs after school.

\section{Methods}

This study involved 204 students in the 2nd-4th grades of two schools in Moscow, whose parents agreed to the children's participation in the study. The survey was conducted in January 2019. The average age of children was $8.76 \pm 0.77$ years, weight $-33.6 \pm 8.0 \mathrm{~kg}$, and height $-137.1 \pm 7.8 \mathrm{~cm}$. The sex ratio was as follows: girls $-42.6 \%$ and boys $-57.4 \% .173$ children were engaged in sports clubs, while 31 attended only physical education classes at school.

All children were screened for posture using the mobile application "PostureScreenMobil", which is widely used for this purpose [16-23].

The data obtained were processed using Student's t-test.

\section{Results}

The results of the photometry of primary school children in terms of "head inclination in the frontal plane" are shown in Figure 1.

There was a zero percent deviation in children involved in figure skating. The percentage of deviations with head inclinations to the right and left was low in children doing gymnastics/acrobatics and sambo/judo (18.7\% and 19.9\%). In groups of children not engaged in sports or engaged in swimming, volleyball, and basketball, more deviations were found $(70.9 \%$ and $66.6 \%)$.

Figure 2 shows the data characterizing the "body inclination in the frontal plane" index. The diagram shows that the highest percentage of deviations in the body position was identified in children engaged in volleyball and basketball (44.4\%) and in the group of children who attended swimming (38.8\%), karate, aikido, and boxing $(17.6 \%)$ and who did not participate in sports (35.4\%). Most of them had a recorded torso inclination to the left. This was especially noticeable in children who played sports, such as football $(27.7 \%)$, volleyball, and basketball (33.3\%).

In groups of children engaged in martial arts, such as sambo and judo, as well as gymnastics with its varieties and dancing, a small percentage of disorders was recorded $(13.2 \%, 12.4 \%$, and $15.7 \%)$. At the same time, the group of children involved in figure skating recorded zero deviations, which indicates that the effect of figure skating on correct posture and symmetrical development is quite effective and favorable compared to other sports and to children who do not participate in sports clubs. 


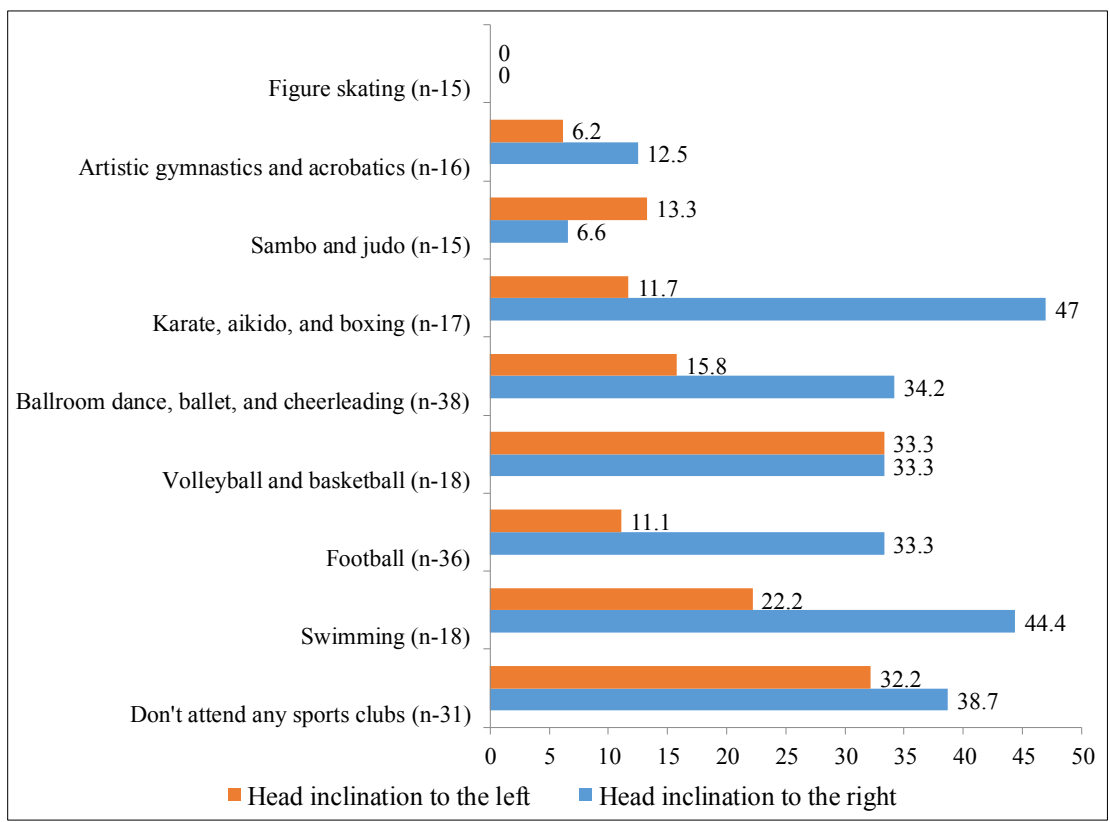

Fig. 1. Head inclination in the frontal plane, frequency of occurrence, $\%$.

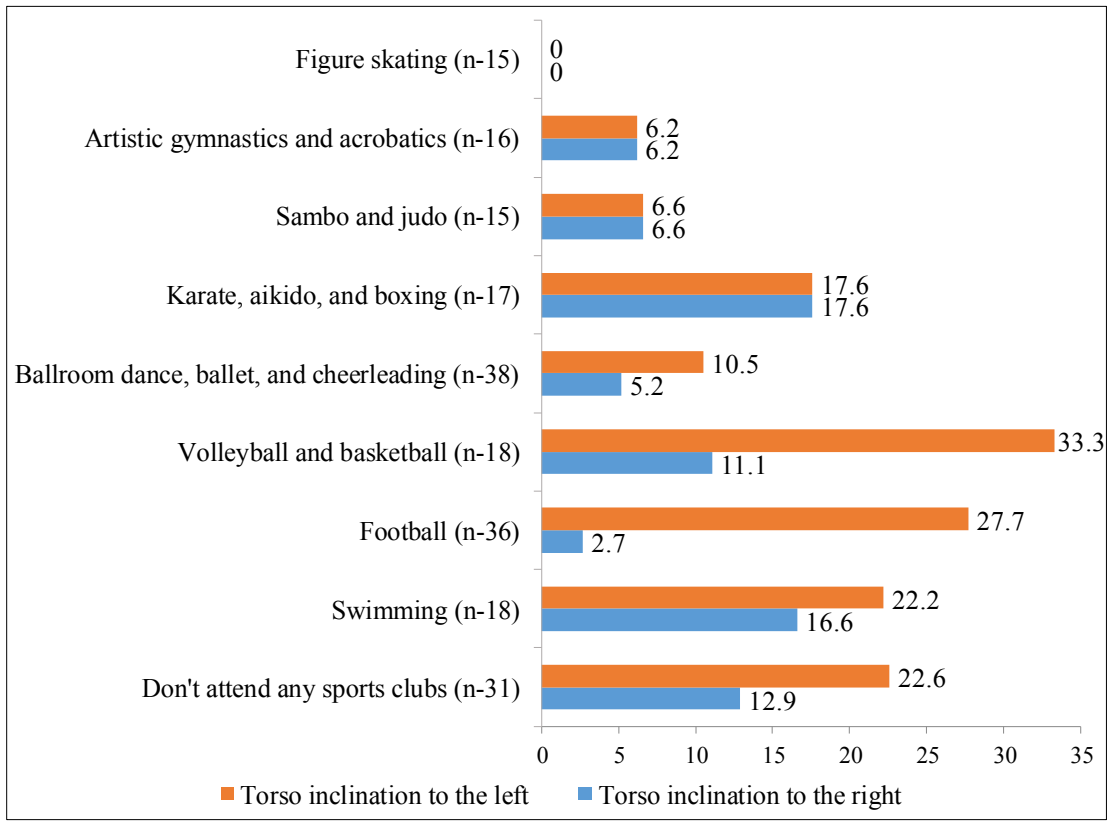

Fig. 2. Body inclination in the frontal plane, frequency of occurrence, $\%$.

Figure 3 shows these posture disorders in terms of "head inclination in the sagittal (lateral) plane". 


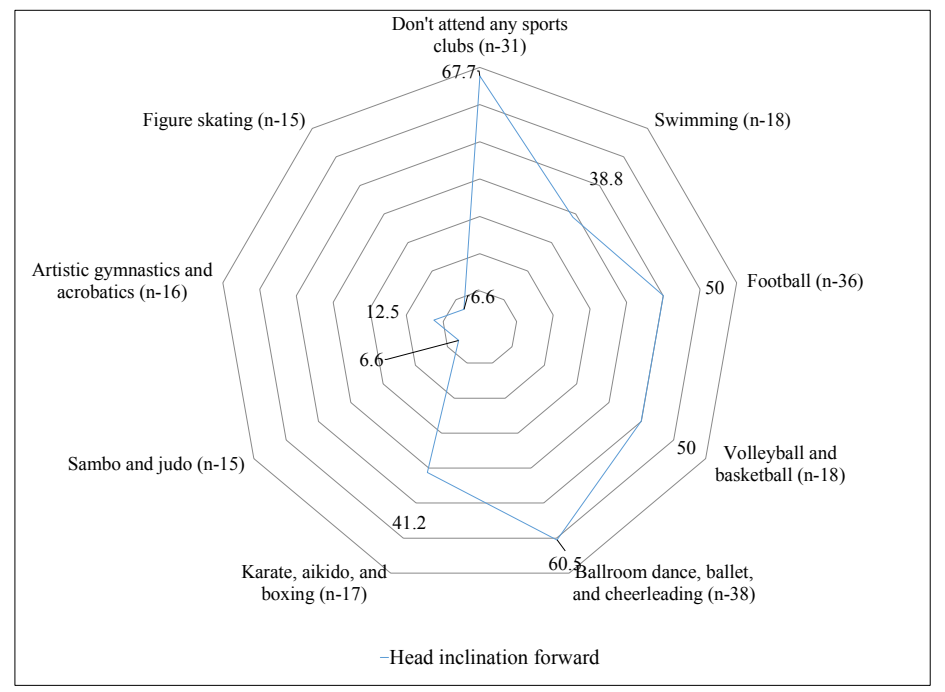

Fig. 3. Results of head inclination forward in the sagittal plane, frequency of occurrence, $\%$.

The study revealed a high percentage of deviations by this index $(67.7 \%)$ in children not engaged in sports clubs. The results obtained in groups of children engaged in figure skating, gymnastics and acrobatics, sambo and judo $(6.6 \%, 12.5 \%$, and $6.6 \%)$ as the lowest indicate that physical exercises in these sports significantly correct posture. This positive effect is also due to the fact that children started these sports at an early age (3-4 years) and by the time of the survey had had a sufficiently formed muscle corset that allowed them to keep their head upright. Sambo wrestlers have a positive effect on correct posture formation even faster - the mentioned index was achieved in a shorter period (enrolment in this sport starts at the age of 7).

Figure 4 shows a diagram reflecting the percentage of children with poor posture by the "shoulder joint displacement in the sagittal plane" index.

Children involved in figure skating, artistic gymnastics, and acrobatics also had no deviations in this index. However, in the group of children involved in sambo and judo, deviations in the shoulder shift index were almost $20 \%$. Even larger deviations $(30-40 \%)$ were recorded in groups of children involved in football, swimming, martial arts, and various types of dancing. The highest percentage of deviations were observed in children who did not participate in any sports club and who attended volleyball and basketball $(41.9 \%$ and $44.4 \%$, respectively). The reason is that physical activity in these sports is aimed at developing strength, speed, and endurance and is ineffective in terms of muscle corset formation. 


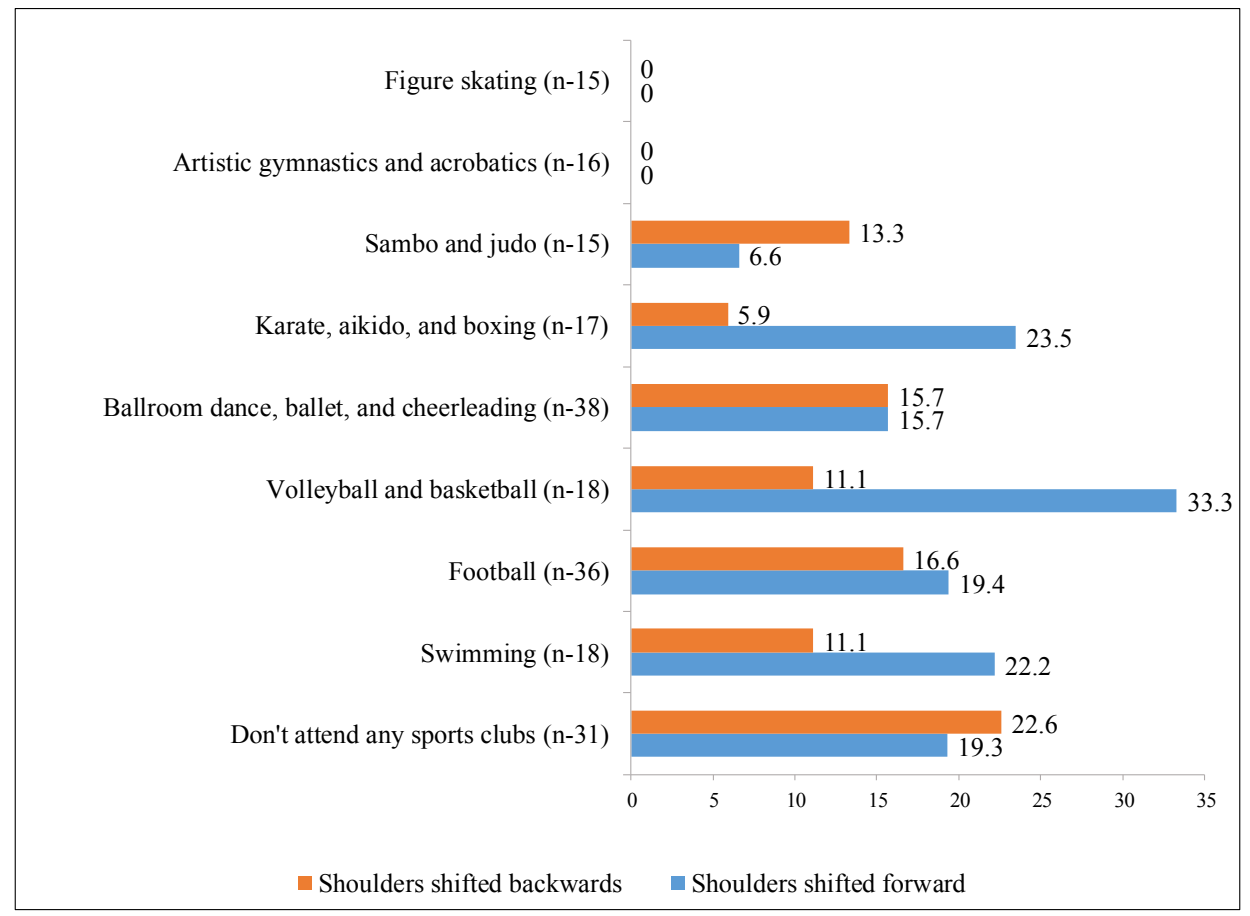

Fig. 4. Displacement of shoulder joints in the sagittal plane, frequency of occurrence, $\%$.

Table 1 presents a summary of the frequency of frontal and sagittal posture disorders in children.

Table 1. Total frequency of posture disorders in the group, $\%$.

\begin{tabular}{|l|c|}
\hline \multicolumn{1}{|c|}{ Sports clubs } & \multicolumn{1}{|c|}{$\begin{array}{c}\text { In total with } \\
\text { disorders }\end{array}$} \\
\hline Figure skating (n-15) & $6.6^{*}$ \\
\hline Artistic gymnastics and acrobatics (n-16) & $25.0^{*}$ \\
\hline Sambo and judo (n-15) & $39.9^{*}$ \\
\hline Karate, aikido, and boxing (n-17) & $64.5^{*}$ \\
\hline Ballroom dance, ballet, and cheerleading (n-38) & $78.8^{*}$ \\
\hline Volleyball and basketball (n-18) & 83.1 \\
\hline Football (n-36) & 83.2 \\
\hline Swimming (n-18) & 83.2 \\
\hline Don't attend any sports clubs (n-31) & 96.6 \\
\hline
\end{tabular}

*The difference is reliable in relation to the "not engaged in sports clubs" index for $\mathrm{p}<0.05$

As can be seen, the most favorable sports for shaping the correct posture of primary school children are figure skating, artistic gymnastics, and acrobatics. The number of children with deviations in these groups was significantly lower. Children involved in sambo and judo had $39.9 \%$ of disorders, which was also significantly less than the number of children in the control group.

The total percentage of posture disorders was higher in martial arts groups such as karate, aikido, boxing, and ballroom dance, but significantly different from the control 
group. The posture of children engaged in game sports (volleyball, basketball, and football) and swimming did not show a significant difference when compared to children who did not participate in sports clubs.

The presented data may indicate a low level of effectiveness of these sports (volleyball, basketball, football, and swimming) for posture or low quality of teaching of these sports. Despite their intensity, training in these sports is often asymmetrical, which is most noticeable in game sports, and does not consider the necessity to strengthen the muscular corset of the child's body.

The highest percentage of deviations from the norm (96.6\%) was recorded in the group of children not engaged in sports, whose physical activity was limited only to physical education lessons. This indicates that physical education lessons are insufficient in the school curriculum or that they are not conducted at the required level.

\section{Discussion}

The results of the research showed that primary school children involved in various types of sports after school were less likely to show signs of posture disorders than children not involved in sports but attending physical education classes at school. J. Kratenova et al. [6] also indicate that, as a result of preventive examinations of younger school children, posture disorders were diagnosed in $38.5 \%$ of them. We agree with J. Moeijes [14] that sports activities have a positive impact on the quality of life and health of children and, consequently, their posture. In our study, we assumed that different sports can have different effects on posture. N. Itamar et al. [24] note that special physical training improves balance control and posture. In doing so, they focus on the type of sport. O. Tomenko et al. [25] cite a comparative analysis of children engaged in sports clubs with children engaged only in physical training according to the school curriculum and prove that the health effects depend on the specifics of the sport.

The study confirms once again that it is not enough to participate in a sports club in raising a harmoniously developed child with the right posture. The early sports specialization that exists today, when children start doing a particular sport from an early age, certainly brings results: after 4-5 years, they start playing football, swimming, acquiring martial arts skills, and dancing well. However, to achieve correct posture and harmonious development of the musculoskeletal system, a comprehensive approach is required, which excludes any asymmetry and unevenness. Not all children will be able to do figure skating, but the process of training, for example, in game sports, can be complemented by exercises aimed at forming the correct posture, thus paying more attention to general physical preparation and improving the physical health of a child [26].

\section{Conclusion}

The data obtained in the study allows us to talk about useful and harmful physical activities for the posture of young school children. However, the highest percentage of posture disorders was recorded in children who did not attend sports clubs and whose physical activity was limited only to school physical education lessons.

The results indicate the necessity to develop new, scientifically justified practical recommendations for physical education teachers and sports coaches on the organization of physical education lessons at school and sports classes after school. The physical activity programs for school children should consider the impact of different sports on the posture of children and include the most effective sets of exercises for its preservation. 


\section{References}

1. A. Topczewska-Cabanek, H. Misiewicz, A. Nitsch-Osuch, E. Gyrczuk, K. Zycińska, K.A. Wardyn, Family Medicine and Primary Care Review, 15(3), 414-416 (2013)

2. J.F. Mahlknech, Jurnal "Zeitschrift fur Orthopadie und Unfallchirurgie", 145(04), 440440 (2007)

3. L. Li, Sch. Health., 39, 1416-1418 (2018)

4. H. Gil, T. Santos, S. Hon Ório, International Symposium on Computers in Education (SIIE) (2018)

5. M. Dolphens, B. Cagnie, P. Coorevits, G. Vanderstraeten, G. Cardon, R. D'hooge, L. Danneels, Spine (Phila Pa 1976), 37(19), 1657-1666 (2012)

6. J. Kratenová, K. Žejglicová, M. Malý, V. Filipová, The Journal of School Health, 77(3), 131-137 (2007)

7. M.E. Gh, A.Alilou, S. Ghafurinia, S. Fereydounnia, Biomedical Human Kinetics, 4(1), 121-126 (2012)

8. B. Wirth, C. Knecht, K. Humphreys, BMC pediatrics, 13(1), 159 (2013)

9. J-H. Lee, Journal of physical therapy science, 28(1), 274-277 (2016)

10. S. Motylewski, A. Zientala, A. Pawlicka-Lisowska, E Poziomska-Piątkowska, Polski merkuriusz lekarski: organ Polskiego Towarzystwa Lekarskiego, 39(234), 36837(2015)

11. M.M. Bezrukikh, V.D. Sonkin, D.A. Farber. Age physiology (physiology of child development): textbook for universities 3, 415 (2008)

12. L.M. Lanningham-Foster, T.B. Jensen, S.K. McCrady, L.J. Nysse, R.C. Foster, J.A. Levine, Medicine \& Science in Sports \& Exercise, 37, 1800-1805 (2005)

13. M. Rahmani Ghobadi, M. Forghani Ozrudi, Physical Education of Students, 23(4), 198-201 (2019)

14. J. Moeijes, J.T. van Busschbach, R.J. Bosscher, J.W.R. Twisk, Quality of Life Research, 28(9), 2453-2469 (2019)

15. I.V. Ryabova, T. Sobolevskaya, N. Nezhkina, D.N. Chernogorov, M.A. Pravdov, S.N. Filippova, Yu.A. Matveev, S.I. Alekseeva, O.V. Melkadze, O.M. Zverev, Prevention and correction of posture disorders in children in learning (Moscow City Pedagogical University, Moscow, 2019)

16. D.M. Boland, B.A. Dolezal, C.B. Cooper, E.V. Neufeld, J. Ruddell, Journal of Physical Therapy Science, 28(12), 3398-3402 (2016)

17. K.A. Szucs, E.V.D. Brown, Journal of Physical Therapy Science, 30(1), 31-36 (2018)

18. N.H. Al-Rawi, H. Yousef, M. Khamis, O. Belkadi, S. Ahmed, S. Ali, The journal of contemporary dental practice, 19(7), 773-777 (2018)

19. C.M.Gubbels, P.A. Oakely, J. McAviney, D.E. Harrison, B.T. Brown, 31(2), 159-165 (2019)

20. G. Cosma, I. Ilinca, L. Rusu, C. Nanu, A. Burileanu, Sport and Kinetotherapy Journal, Vol. XI, 1(39), 58-64 (2015)

21. P.A. Oakley, D.E. Harrison, J.M. Anderson, Journal of Physical Therapy Science, 31(2), 153-158 (2019)

22. A. Bogdani, G. Pano, Journal Of Human Sport \& Exercise, 11(1), 245-250 (2016)

23. E. Tarakci, N. Arman, S. Sahin, A. Adrovic, K. Barut, O. Kasapcopur, Congress of the European-League-Against-Rheumatism (EULAR), 77, 1809 (2018) 
24. N. Itamar, D. Schwartz, I. Melzer, Journal of Sports Medicine and Physical Fitness, 53(5), 483-489 (2013)

25. O. Tomenko, L. Kirichenko, I. Skripka, Y. Kopytina, A. Burla, Journal of Physical Education and Sport, 17(3), 1095-1100 (2017)

26. L.R. Bosso, A.R.C. Golias, Revista Brasileira de Medicina Do Esporte, 18(5), 333-337 (2012) 